\title{
Development of a New Biaxial Testing System for Generating Forming Limit Diagrams for Sheet Metals Under Hot Stamping Conditions
}

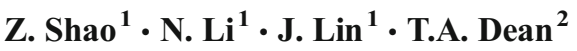

Received: 30 December 2015 / Accepted: 31 May 2016 / Published online: 15 June 2016

(C) The Author(s) 2016. This article is published with open access at Springerlink.com

\begin{abstract}
Conventional experimental approaches used to generate forming limit diagrams (FLDs) for sheet metals at different linear strain paths are not applicable to hot stamping and cold die quenching processes because cooling occurs prior to deformation and consistent values of heating rate, cooling rate, deformation temperature and strain rate are not easy to obtain. A novel biaxial testing system for use in a Gleeble testing machine has been adopted to generate forming limits of sheet metals, including aluminium alloys, magnesium alloys and boron steel, under practical hot stamping conditions in which heating and cooling occur. For example, the soaking temperature is about $900{ }^{\circ} \mathrm{C}$ and the deformation temperature range is $550-850{ }^{\circ} \mathrm{C}$ for boron steel [1] and the soaking temperature is about $535{ }^{\circ} \mathrm{C}$ and the deformation temperature range is $370-510{ }^{\circ} \mathrm{C}$ for AA6082 [2]. Resistance heating and air cooling were introduced in this pioneering system and the thermal analysis of different heating and cooling strategies was investigated based on a type of cruciform specimen. FE models with a UAMP subroutine were used to predict temperature fields on a specimen in ABAQUS 6.12. Digital image correlation (DIC) system was used to record strain fields of a specimen by capturing images throughout the deformation history and its postprocessing software ARAMIS was used to determine forming limits according to ISO standards embedded in the software. Heating and cooling strategies were determined after the
\end{abstract}

N. Li

n.li09@imperial.ac.uk

1 Department of Mechanical Engineering, Imperial College London, London SW7 2AZ, UK

2 School of Mechanical Engineering, University of Birmingham, Edgbaston, Birmingham B15 2TT, UK analysis. Preliminary results of forming limit curves at the designated temperatures are presented in order to verify the feasibility of this new method.

Keywords Sheet metal forming · Hot stamping · Formability tests $\cdot$ Forming limit diagram (FLD) $\cdot$ Novel biaxial testing system $\cdot$ Thermal analysis

\section{Introduction}

Weight reduction can improve the performance of automobiles and can directly reduce energy consumption [3]. Two potential routes for reducing the weight of sheet metal parts in automobile body structures are the use of high strength steel, which enables a thinner gauge sheet to be used and the use of sheet of low density, such as aluminium alloys. High strength steel is difficult to form and aluminium alloys have low formability at room temperature and, to deal with this, hot forming technologies have been developed; they are hot stamping and cold die quenching for steel and solution heat treatment, forming and in-die quenching $(\mathrm{HFQ} ®)$, for lightweight alloys [4].

The hot stamping and cold die quenching process, conventionally abbreviated to hot stamping, is used to obtain complex shaped components with high mechanical properties. In the hot stamping process, heat treatable metal sheet is heated to a temperature at which it is a solid solution with a single phase, transferred to a press and simultaneously formed and quenched in a cold tool [5]. The control of die temperature, cooling rate, forming speed and metallic sheet temperature are critical conditions for the success of these processes. The technique can be applied to both quenchable steels, such as boron steel [5], and heat treatable low density sheet metals, such as aluminium alloys [6] and magnesium alloys [7]. For the latter 
application, a patented process named $\mathrm{HFQ}{ }^{\circledR}$ has been developed [8]. In the $\mathrm{HFQ}{ }^{\circledR}$ process, a metal sheet is heated to a temperature at which its microstructure is a solid solution and then transferred to a press and simultaneously formed and quenched in a cold tool from which it emerges with a microstructure of solid solution virtually completely retained [9, 10]. This novel process is beneficial to forming complex shaped parts in one operation at a low cost. To be successful, forming conditions, such as heating rate, cooling rate, forming temperature and strain rate, need to be controlled [11].

The forming limit diagram (FLD) is a traditional and useful tool to evaluate the formability of sheet metals [12], as shown in Fig. 1(a). The key feature of an FLD is the forming limit curve, which identifies the boundary between uniform deformation and the onset of plastic instability. The shape of an FLD of a material formed at elevated temperature varies greatly from one formed at room temperature. At an isothermal test condition, constant strain rate and proportional strain paths [13] are required for the determination of forming limit curves at elevated temperatures. FLDs for sheet metals are usually obtained experimentally by formability tests and different types of testing methods have been proposed. These include; varying the dimensions of specimens [14] and shapes of elliptical dies in the hydraulic bulge test [15] or shape of punch in the biaxial stretching test [16]. At present, two types of test approach are commonly used to determine limit strains; they are the out-of-plane test and the in-plane test, as shown diagrammatically in Fig. 1(b) and (c).

In the out-of-plane test, such as the Nakazima test (Fig. 1(b)) [17], waisted specimens with different parallel shaft lengths are stretched by a rigid hemispherical punch. The application of the out-of-plane test at ambient temperature has been standardised and has also been used to obtain FLDs at high temperature. Ayres et al. [18] used this experimental method to investigate temperature and strain rate effects on the formability of AA5182 by heating the spherical punch and die to a temperature of 130 and $200{ }^{\circ} \mathrm{C}$, respectively. Bagheriasl [19] used this test to obtain the FLD of AA3003 at 100 $350{ }^{\circ} \mathrm{C}$ and strain rates of $0.003-0.1 / \mathrm{s}$. Circular grid patterns of $2 \mathrm{~mm}$ diameter were etched on specimens prior to forming, and the digital image correlation (DIC) technique [20] was adopted to measure strains. DIC enables full-field strains to be measured at different stages of forming by comparing the digital images of a pattern sprayed on a specimen. Min et al. [21] obtained the left-hand side of an FLD for boron steel at a temperature of approximately $800{ }^{\circ} \mathrm{C}$ for hot stamping applications. However, deformation temperature cannot be controlled precisely in the transfer of specimen from furnace to cold tooling. Pneumatic stretching was used by Abu-Farha et al. [22] to determine the formability of magnesium AZ31B sheet heated to $400{ }^{\circ} \mathrm{C}$. In contrast to isothermal testing, the need to simultaneously quench and form, to simulate HFQ ${ }^{\circledR}$ conditions makes testing in a furnace impractical. For

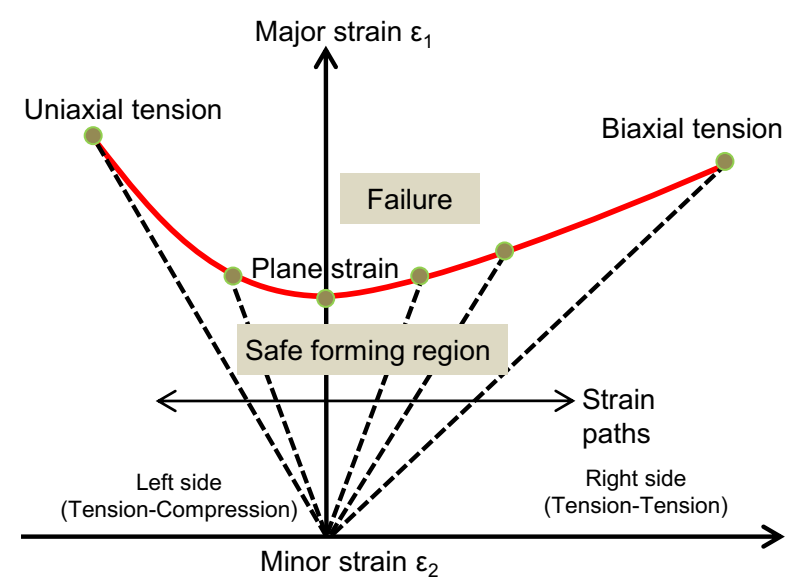

(a) Characteristics of an FLD

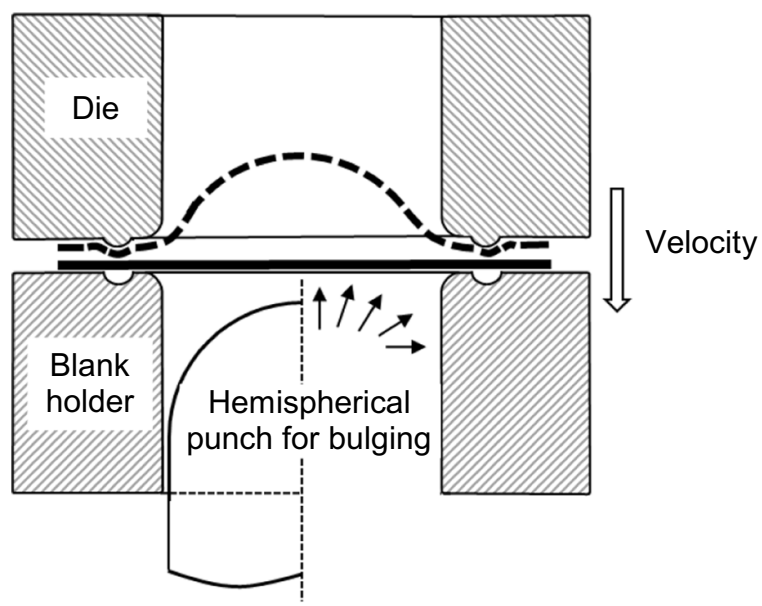

(b) The typical out-of-plane test setup

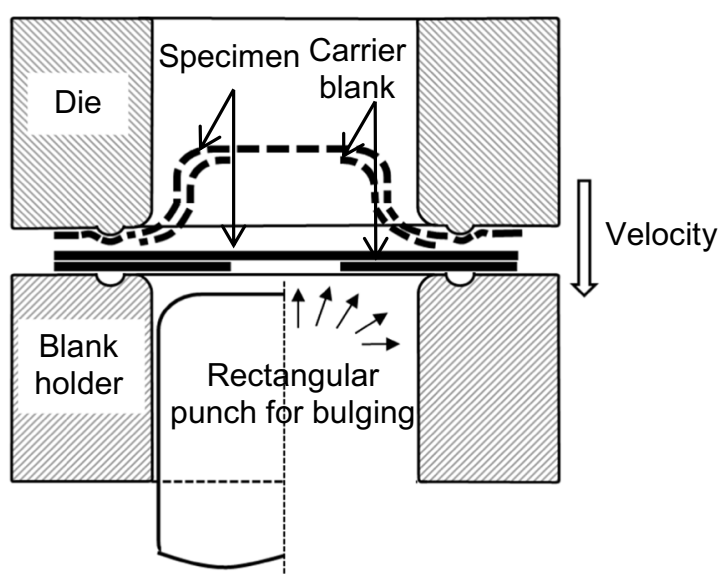

(c) The typical in-plane test setup

Fig. 1 Schematics showing the testing methods for generating forming limit diagrams (FLDs) for hot stamping applications

the in-plane test, such as the Marciniak test (Fig. 1(c)) [23], specimens are stretched over a flat-bottomed punch of cylindrical or elliptical cross section without imposing any bending 
within the central region of the specimen. A carrier blank with a central hole is often used to eliminate frictional contact between specimen and the punch. Li and Ghosh [24] preformed a biaxial warm forming investigation of AA5754, AA5182 and AA6111 by forming rectangular parts at a rapid rate of 1 $/ \mathrm{s}$ and a temperature range of $200-350{ }^{\circ} \mathrm{C}$. No data was obtained at temperatures over $350^{\circ} \mathrm{C}$. Kim et al. [25] established the FLD of Al5182+Mn alloy at three different temperature levels $\left(250{ }^{\circ} \mathrm{C}, 300\right.$ and $\left.350{ }^{\circ} \mathrm{C}\right)$ for isothermal conditions. Palumbo et al. [26] performed isothermal warm formability tests using an electrically heated punch which heated the specimen by heat transfer. FLDs of AA5754 were obtained in the temperature range of $20-300^{\circ} \mathrm{C}$. Neither current conventional out-of-plane nor in-plane methods of determining FLDs are suitable for hot stamping and cold die quenching conditions. Using a planar biaxial machine with a cruciform specimen could be an alternative approach to determine the forming limits. Hannon and Tiernan [27] reviewed planar biaxial tensile test systems for sheet metal and classified the test machines to two types i.e. stand-alone biaxial testing machines and link mechanism attachments for biaxial testing. Zidane et al. [28] proposed a new cruciform design for formability tests and obtained the FLD of AA5086 at room temperature based on a servo-hydraulic biaxial test machine. Naka et al. [29] used biaxial tensile tests and hot air blow heating with cruciform specimens to investigate the effects of strain rate and temperature on yield locus of AZ31.

These methods are usually used to determine FLDs at room temperature and only a few investigations concentrate on formability tests at elevated temperature. In cold stamping conditions, the FLD of a material contains only one curve. However, the FLD of a material at elevated temperature consists of many curves, relating to process conditions [30]. It is very difficult to obtain the FLD of a material under hot stamping and cold die quenching conditions at varying deformation rates because extra heating and cooling facilities are needed, control of heating rate, cooling rate, temperature and strain rate are hard to obtain precisely and the problem of the difficulty of strain measurement in a hot environment needs to be solved. The work described in this paper concerns a novel system for dealing with these problems.

In this paper, a novel biaxial testing system, for use on a Gleeble materials simulator is described, for obtaining FLDs of alloy sheet under hot stamping conditions. Different proportional strain paths can be achieved and friction effects can be avoided. A cruciform specimen was proposed for the biaxial testing. A thermal analysis of the resistance heating method adopted is presented, in order to improve the uniformity of temperature distribution in the specimen during the testing. Different strain paths are verified to be linear and results of an experimental FLD are shown in this paper to prove the feasibility of this new testing system for hot stamping and cold die quenching applications.

\section{The Principles of the Experimental Design}

The temperature profile applied to the hot stamping process is presented schematically in Fig. 2(a). Since the shape and position of a forming limit curve is sensitive to temperature and strain rate, deformation of the specimen should be performed at constant temperature and constant strain rate. A schematic of the required temperature profile is shown in Fig. 2(b). Heating rate and cooling rate are also critical parameters for the HFQ ${ }^{\circledR}$ process and should be controlled accurately to maintain a supersaturated solid solution without grain degradation in a specimen. Aluminium alloy 6082-T6, which is extensively used in the automotive industry [31], was used as the sample material to carry out the investigation. The specimen was heated to the solution heat treatment temperature $535{ }^{\circ} \mathrm{C}$ [32] at a heating rate of $30{ }^{\circ} \mathrm{C} / \mathrm{s}$, soaked for $1 \mathrm{~min}$ and then cooled to a designated temperature in the range of $370-510{ }^{\circ} \mathrm{C}$ at a cooling rate of $100^{\circ} \mathrm{C} / \mathrm{s}$ [2]. The tensile tests at different strain paths; uniaxial, plane strain and biaxial

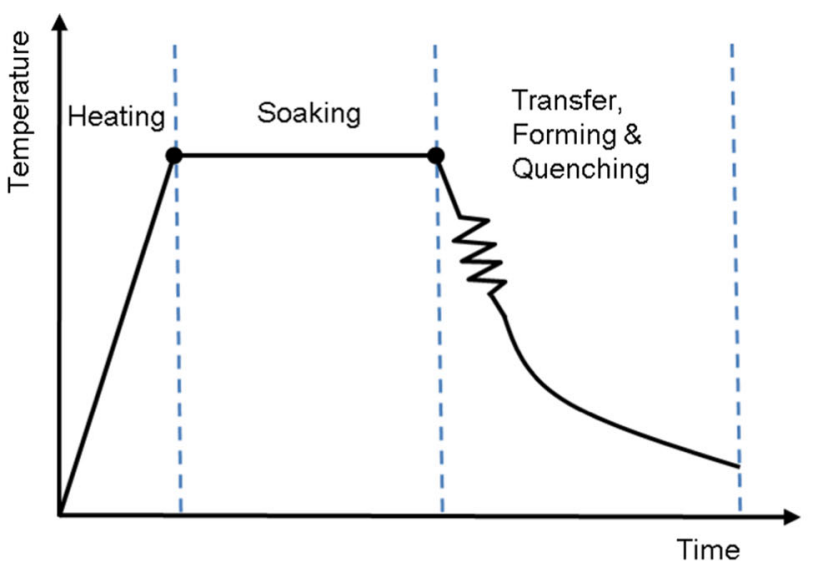

(a) Temperature profile of a hot stamping process

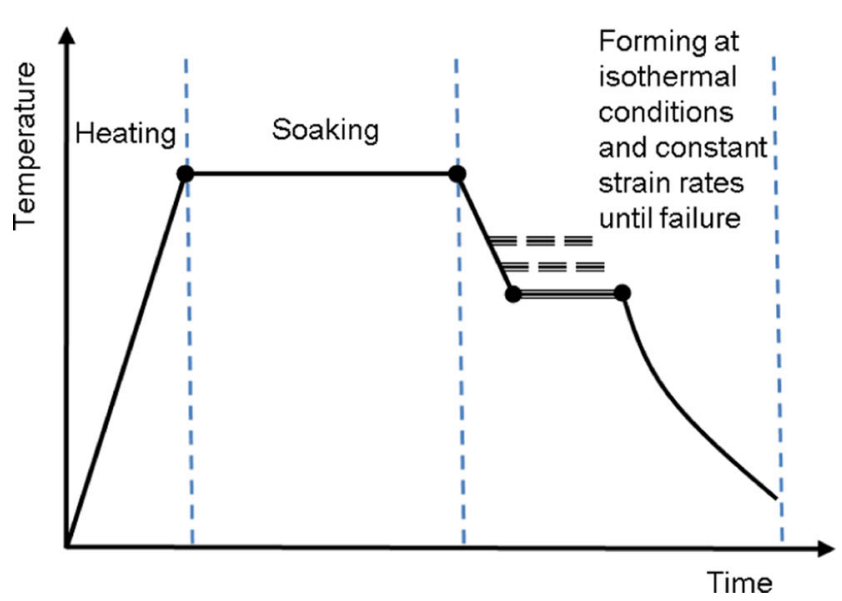

(b) Temperature profile of test requirements

Fig. 2 Schematics showing the temperature profiles in (a) hot stamping process and (b) the test requirements for generating FLD data 
testing, were conducted at constant strain rate in the range of $0.01-1 / \mathrm{s}$.

The fully integrated closed loop control in-plane thermomechanical testing device contains a heating system, a cooling system, an automatic feedback control system, a biaxial mechanism, a strain rate control system and a strain and loading measurement system. A flow chart of the entire testing system is shown in Fig. 3. Different heating and cooling methods which can be chosen are listed in the figure. Facilities on the Gleeble were used to control heating rate, cooling rate and create a final isothermal testing condition after cooling. The direct resistance heating system of the Gleeble 3800 can heat specimens at rates of up to $10,000{ }^{\circ} \mathrm{C} / \mathrm{s}$ accurately and can hold a steady-state equilibrium temperature. The environmental chamber of the Gleeble is kept at room temperature during the testing. Cooling rate is a critical condition for hot stamping process and air jet cooling was connected to the quench system to control the cooling rate. Since only uniaxial tension/ compression can be obtained on a standard Gleeble [33], an ad-hoc test apparatus was used to transform uniaxial tension to biaxial tension under different loading ratios, so that different strain paths were realised. A high speed camera with the DIC system was used to capture the speckle pattern pre-painted on the surface of the concerned central area of the specimen and the stochastic pattern does not degrade at temperatures below $1093{ }^{\circ} \mathrm{C}$. The ARIMIS software was used for the data processing to obtain time-dependent full strain fields during deformation.

\section{Biaxial Testing Apparatus}

The biaxial testing apparatus, as shown in Fig. 4, was designed to be used on a Gleeble 3800. It can convert an input uniaxial force into an output bi-axial force. To fit within the Gleeble chamber, the overall dimensions of the apparatus were $250 \times 250 \times 90 \mathrm{~mm}$. Its loading capacity of $40 \mathrm{KN}$ enables it to be used for testing aluminium alloys, magnesium alloys and boron steel, with thickness in the range of 0.5 $3 \mathrm{~mm}$. The clamp-1 in the backside is connected directly to the movable jaw of the Gleeble, which provides a uniaxial tensile force to rotate the input rotatable plate 3 . The input rotatable plate 3 is coupled to the drive shaft- 2 which in turn drives the output rotatable plate 4 . The rotation of the output rotatable plate 4 drives the four coupled connecting rods-5, which are pivotably coupled to the connection points of the output rotatable plate 4 , to slide which cause the carriages- 6 to slide along the guide rails-7 so that a biaxial force is applied to the specimen- 8 , each arm of which is clamped to a carriage by a specimen holder-9 and top plate 10 [34]. Thermocouples are welded on the central region of the specimen on the backside and linked to the Gleeble feedback temperature control system to monitor the temperature changing history on the specimen. Connecting rods with different lengths are employed to generate different strain paths, through plane strain, biaxial strain to uniaxial strain. In order to achieve uniaxial strain path, two opposing carriages- 6 are disconnected from the output rotatable plate 4 and the specimen is held only by the other two opposing carriages-6. Plane strain can be achieved by fixing the positions of two opposing carriages thus preventing specimen deformation between them. Two pairs of connecting rods with same or different lengths and orientations can be used and by changing the length of corresponding connecting rods, strains of various degrees of bi-axiality can be obtained.

Figure 5 is a photograph of the set-up of the entire experimental system using the Gleeble 3800. Two miniature load cells (13-load cells in Fig. 4) are installed in the new test rig and connected to a strain gauge amplifier and an oscilloscope, which can capture the history of the loading. Different framing rates for the high-speed camera could be used to correspond with different experimental strain rates. For example, the framing rate was 25, 50 and $500 \mathrm{fps}$, for the tests at a strain rate of $0.01,0.1$ and $1 / \mathrm{s}$, respectively. There are four clamping regions on the four arms of one cruciform specimen. Each clamping region is contacted tightly with top plates made of stainless steel which are electrodes for resistance heating. To
Fig. 3 System configuration of the planar thermo-mechanical testing system

\begin{tabular}{|c|c|c|}
\hline $\begin{array}{l}\text { Thermal System, } \\
\text { 1) Resistance heating system } \\
\text { 2) Induction heating system } \\
\text { 3) Conduction heating method } \\
\text { 4) A combination of above }\end{array}$ & \multirow{2}{*}{$\begin{array}{l}\text { The fully integrated closed } \\
\text { loop control in-plane } \\
\text { thermo-mechanical testing } \\
\text { system for the } \\
\text { determination of FLD under } \\
\text { hot forming and cold die } \\
\text { quenching conditions }\end{array}$} & $\begin{array}{l}\text { Biaxial mechanism, } \\
\text { 1) Stand-alone biaxial } \\
\text { test machine } \\
\text { 2) Link mechanism } \\
\text { attachments }\end{array}$ \\
\hline $\begin{array}{l}\text { Quench System, } \\
\text { 1) Convection cooling system } \\
\text { 2) Conduction cooling method } \\
\text { 3) A combination of above }\end{array}$ & & $\begin{array}{l}\text { Strain rate control system, } \\
\text { 1) Define the relationship } \\
\text { of tensile time and } \\
\text { displacement }\end{array}$ \\
\hline $\begin{array}{l}\text { Automatic feedback control system, } \\
\text { 1) Time-dependent } \\
\text { temperature control } \\
\text { 2) Feedback control of } \\
\text { specimen temperatures }\end{array}$ & & $\begin{array}{l}\text { Strain and loading } \\
\text { measurement, } \\
\text { 1) DIC system for strain } \\
\text { measurement } \\
\text { 2) Load cell for loading } \\
\text { measurement }\end{array}$ \\
\hline
\end{tabular}




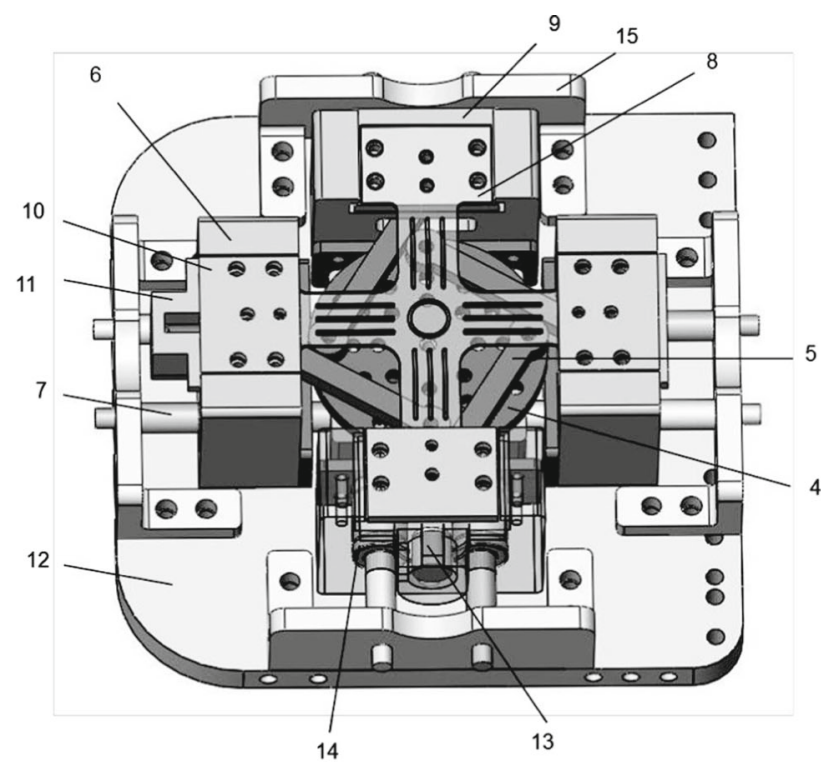

(a) The front view of the novel test rig

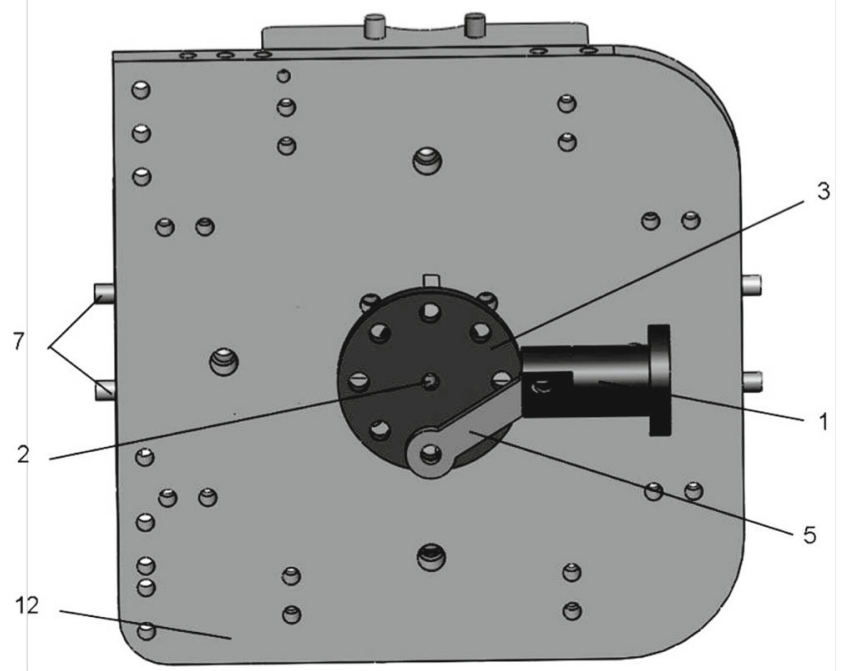

(b) The back view of the novel test rig

Fig. 4 3D diagram of the novel biaxial test rig (1-clamp, 2-drive shaft, 3input rotatable plate, 4- output rotatable plate, 5-connecting rods, 6carriages, 7-guide rail, 8-specimen, 9-specimen holders, 10-top plates, 11-specimen holder with load cells, 12-base plate, 13-load cells, 14linear bearing, 15-stops)

resistance heat the specimens, cables with uninsulated tin plated crimp ring terminals were used to connect the top plates to the Gleeble power supply. Flared nozzles with hoses were connected to the high flow quench system with a maximum regulated air of $120 \mathrm{psi}$ to quench the entire surface of a specimen. The nozzles are not directed onto the gauge section for cooling to avoid blocking the central region in the camera view.

Compared with the conventional out-of-plane and in-plane formability tests, the present method overcomes their obvious drawbacks of the presence of friction and formed shape

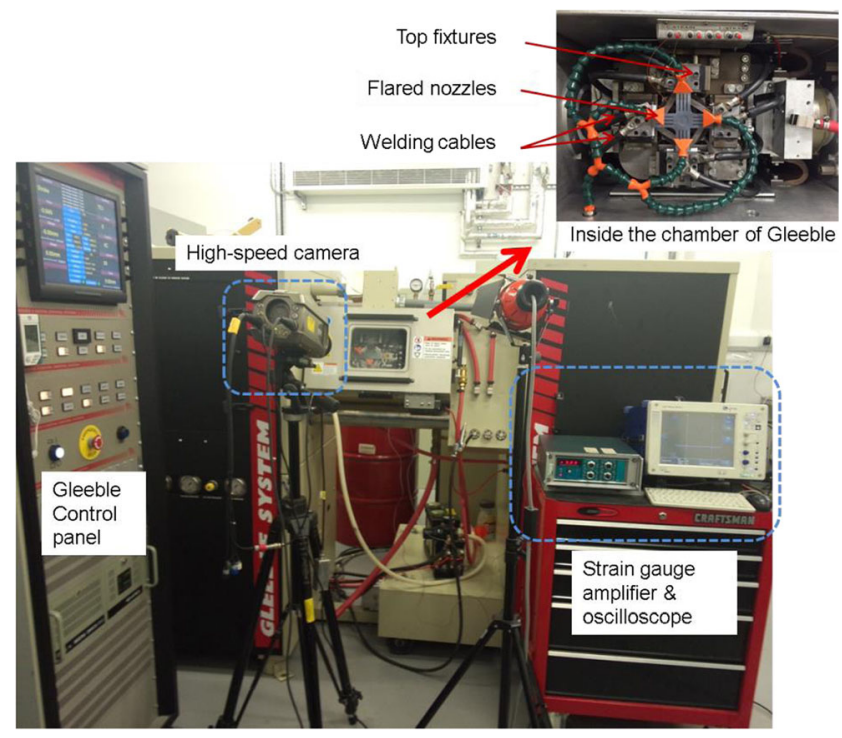

Fig. 5 The set-up of the entire experimental system

complexity. The mechanism has a relatively simple configuration and is employable within limited space on conventional tensile test machines. The heating rate and cooling rate can be controlled precisely by a Gleeble for complex forming process applications. A controllable temperature distribution can be created in the gauge region of a specimen. The maximum temperature to which a sheet metal specimen can be heated using this testing system mainly depends on the nature of test material, dimensions of test-piece, and heating power. A steel test-piece of the current design (with thickness $\leq 3 \mathrm{~mm}$ ) can be heated to $1000{ }^{\circ} \mathrm{C}$. The relationship of time and input displacement from a Gleeble can be defined accurately in advance in order to keep a constant effective strain rate on a specimen during testing. Different linear strain paths can be achieved easily by varying the lengths and orientations of rigid connecting rods in the apparatus and the strain path is independent of specimen dimensions. The testing system enables the DIC system to be used so that deformation history of a specimen can be captured.

\section{Development of Specimen Design}

Various cruciform specimens with different features have been designed for biaxial testing [27, 35-37]; however, no standard of specimen geometry for biaxial testing has been developed. Abu-Farha et al. [38] also summarised examples of cruciform specimen geometries for biaxial testing and proposed geometries with tapered thickness to induce plastic deformation in the central gauge area, heated by a heat gun, to a deformation temperature of $300{ }^{\circ} \mathrm{C}$. However, no previously designed cruciform specimens can be used directly in the apparatus described here as for the first time heating is by resistance. The aim of a new cruciform specimen design is to ensure the onset 
of localised necking occurs within the central biaxial loading zone of a specimen and not in the arms, which are uniaxially loaded. Initial designs of specimens, dog bone for uniaxial and cruciform for biaxial tests are shown in Fig. 6. It has been shown that a reduced thickness in the central zone of a cruciform specimen and slots in the arms are beneficial for both inducing failure to occur within the gauge zone and improving the uniformity of strain distribution $[39,40]$.

A dog-bone type of specimen with a $98 \mathrm{~mm}$ parallel length was used for uniaxial testing in the determination of an FLD of AA6082 under the HFQ ${ }^{\circledR}$ conditions. The thickness of the specimen was $1.5 \mathrm{~mm}$ and other dimensions were as shown in Fig. 6(a). The dimensions of cruciform specimens, including clamping regions, are shown in Fig. 6(b). Fillets of $10 \mathrm{~mm}$ exist at the intersection of two adjacent arms, to reduce stress concentration in the corners. The thickness of the specimen was $1.5 \mathrm{~mm}$ except for the $17 \mathrm{~mm}$ diameter central circular gauge region where it was reduced to $0.7 \mathrm{~mm}$, by recessing each face by $0.4 \mathrm{~mm}$. Slots $1.4 \mathrm{~mm}$ wide and $28 \mathrm{~mm}$ long were cut into the arms in order to distribute the load more uniformly to the central gauge region. The distance between each slot is $6 \mathrm{~mm}$ and the distance from the mid-length of the specimen to the ends of the slots is 16.5 mm, marked in Fig. 6(b).

The first stage in developing specimen dimensions was based on uniformity of temperature in the central area at the start of a tensile test. Three types of heating and cooling strategies are possible with cruciform specimen, as shown in Fig. 7. For the first type, one arm of the specimen is connected to the positive

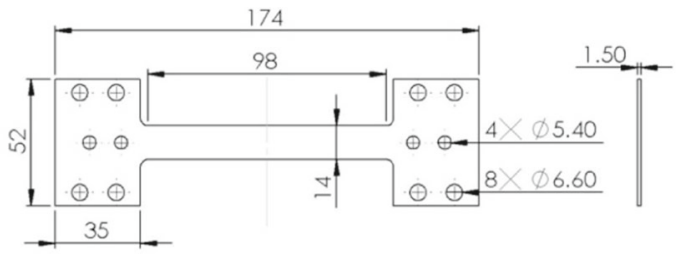

(a) Specimen dimensions for uniaxial tension ( $\mathrm{mm})$

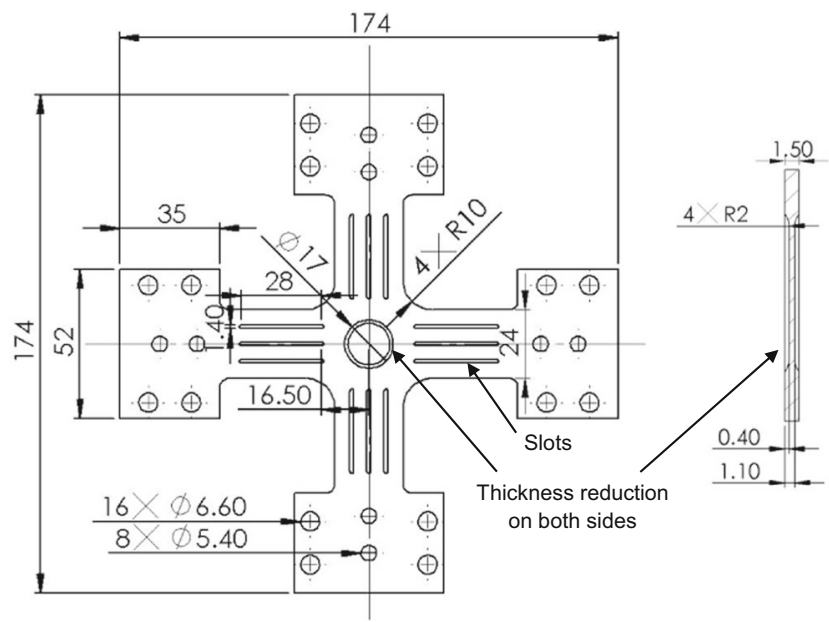

(b) Cruciform specimen dimensions for biaxial tension (mm)

Fig. 6 Schematic diagram of specimens used for the formability test electrode and the opposite one to the negative electrode. Since there is no electrical current flow in the other two arms of the specimen, their temperature remains low. The cooling air can flow from the ends of these two arms to the central region for quenching when the quench is triggered (Fig. 7(a)). This is a simple and straightforward way to achieve the resistance heating and cooling, but the temperature distribution over four arms of the specimen will not be uniform. For the second type, two adjacent arms are attached to positive electrodes and the other two to negative electrodes (Fig. 7(b)). The electrical current goes through the entire specimen to heat it and four nozzles are used for cooling. Cooling air flows from the ends of the four arms to the central region enveloping the entire gauge region of the specimen. For the third type, two opposite arms are attached to positive electrodes and the other two to negative electrodes (Fig. 7(c)). The cooling process is the same as for the second type of cooling strategy. Air flow rate is a critical parameter to
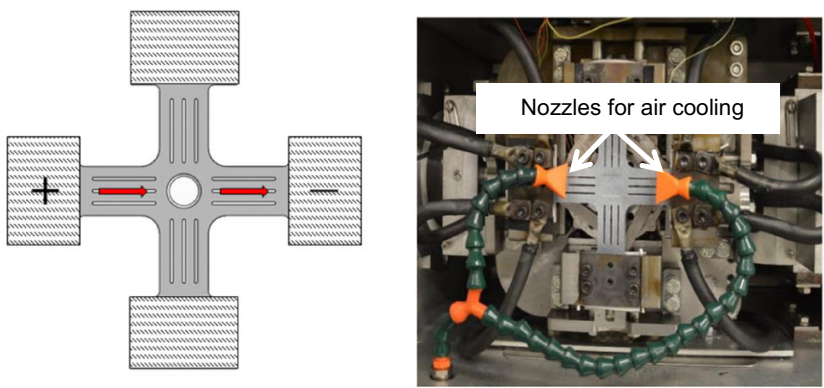

(a) Heating and cooling - Type 1

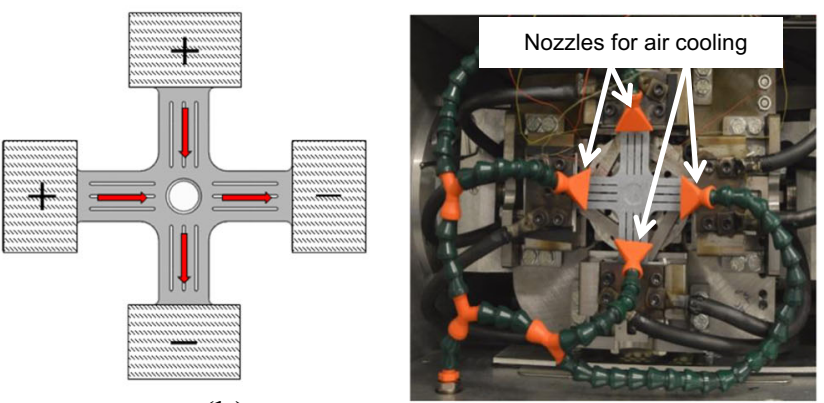

(b) Heating and cooling - Type 2

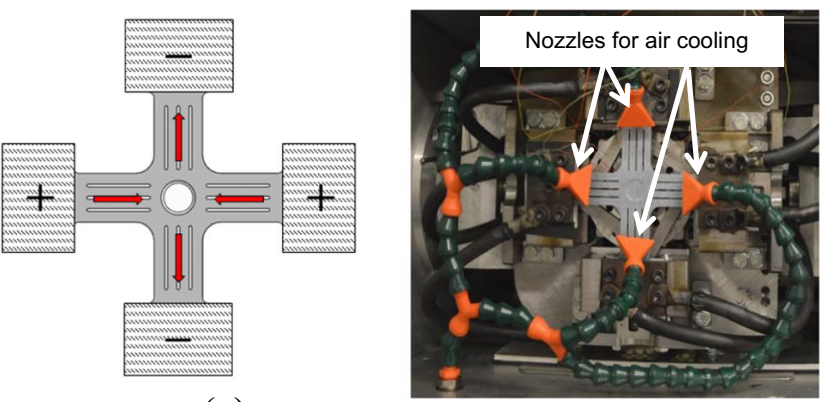

(c) Heating and cooling - Type 3

Fig. 7 Three strategies of specimen heating and cooling (Arrows on specimens represent polarity of electrical potential; Specimen dimensions are shown in Fig. 6(b)) 
control the cooling rate. Flow rate depends on air pressure and the pressure required for a chosen cooling rate depends on specimen dimensions and test temperature. Trials are necessary to identify values of air pressure required to achieve specified cooling rates.

\section{Specimen Temperature Tests}

\section{Experimentation}

Tests were conducted using each of the above three types of heating and cooling strategies to measure the temperature distribution in an undeformed specimen. Pairs of thermocouples were welded on each specimen in order to identify temperature gradients. The locations of the thermocouples and the measured temperature profiles are shown in Fig. 8. Solid lines are the programmed temperature profiles in the Gleeble and dotted lines are the measured temperatures at different locations on the specimen. The temperature of the central point TC1 was used to control the heating and cooling processes according to the designated temperature profile. The heating rate was reduced to 5 from $50{ }^{\circ} \mathrm{C} / \mathrm{s}$ once the temperature reached $500{ }^{\circ} \mathrm{C}$ to avoid overshooting of the target temperature of $535^{\circ} \mathrm{C}$, which is the solution heat treatment temperature for AA6082. The strength of AA6082 decreases with the increasing temperature according to the results of previous uniaxial tensile tests [41]. In order to enable the onset of necking to be started from the central gauge region which is undergoing biaxial loading, in an ideal case, the temperature field in the recessed region should be higher than that in other parts of the specimen and the temperature distribution in the gauge region should be uniform.

Figure 8a shows the temperature at location 3 to be over $10^{\circ} \mathrm{C}$ higher than that at location 1 because of large geometric changes from the end of the slot to the recess in the centre for the first type of heating and cooling strategy. This may cause localised necking to start from the region around location 3 with stress concentration but not from the gauge section, which is not acceptable for the biaxial tension. For the second type of heating and cooling strategy, the temperature difference within the recessed region is within $8^{\circ} \mathrm{C}$, which indicates a sufficiently uniform temperature distribution was created (Fig. 8(b)). The temperature at location 4 is around $20{ }^{\circ} \mathrm{C}$ lower than that at location 1 , which is perhaps beneficial to postponing localised necking outside the gauge section. Regarding the third type of heating and cooling strategy, the temperature at location 1 is $30^{\circ} \mathrm{C}$ lower than that at location 2 (Fig. 8(c)). When the average temperature in the central region is much lower than that of the arms of the specimen, premature localised necking might occur in them. Further investigation is needed to verify the uniformity of deformation within the gauge length region.

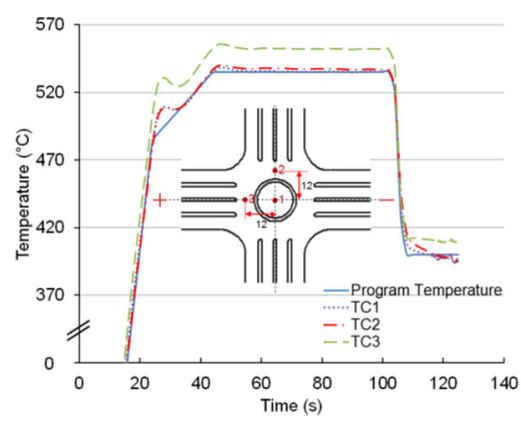

(a) Temperature profile with the heating and cooling strategy of Type 1

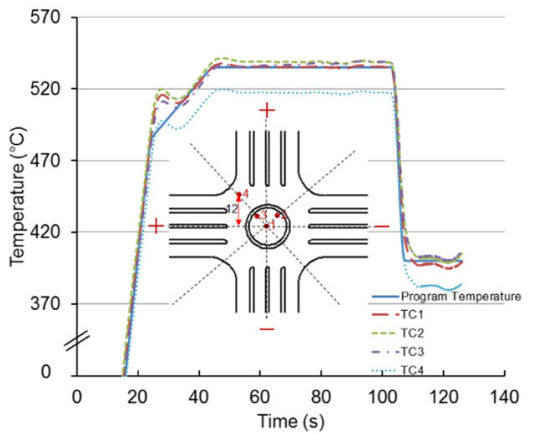

(b) Temperature profile with the heating and cooling strategy of Type 2

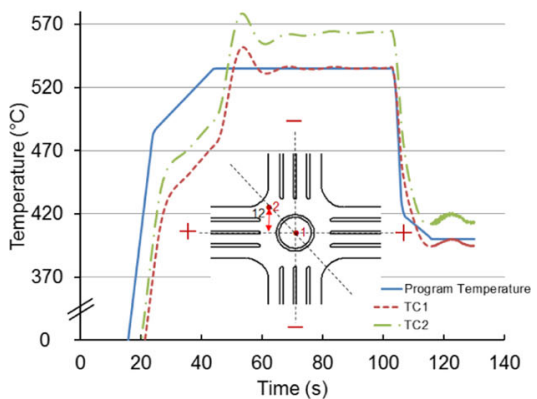

(c) Temperature profile with the heating and cooling strategy of Type 3

Fig. 8 Experimental results of temperature distribution (Numbered dots on specimens are thermocouple locations; ' + ' represents positive electrode and '-' is negative electrode; Specimen dimensions are shown in Fig. 6(b))

Different strategies of heating and cooling have their own advantages and drawbacks. In order to obtain entire temperature fields, which could not be readily obtained experimentally FE simulation was carried out to further investigate the uniformity of temperature distribution and thus enable selection of the best heating and cooling strategy.

\section{FE Simulations}

A thermo-electrical FE model was developed in ABAQUS 6.12 to simulate the Joule heating and calculate the temperature distribution in a specimen. A user-defined subroutine UAMP was embedded in ABAQUS/Standard to control the value of the current density input to the FE model by comparing the error between the calculated temperatures and the temperatures measured experimentally at different locations on 
the specimen. The user subroutine UAMP provided feedback control by regulating the input of current density to simulate resistance heating, illustrated in the flow diagram in Fig. 9.

The controlling thermocouple TC1 was chosen as the central node within the gauge section. An initial value of current density was applied to the model at the start increment of the simulation. The calculated temperature of the controlling node was compared to the predefined temperature at corresponding increment time $t_{i}$. If the difference is equal or less than $0.1{ }^{\circ} \mathrm{C}$, the amplitude of current density would remain constant. If the difference is greater than $0.1{ }^{\circ} \mathrm{C}$, the amplitude would be modified at the next increment of time according to the equation (1) [42]:

$\varnothing_{j}=K_{j}\left(1+\Delta T_{i} /\left(1+T_{i}\right)\right)$

Where, $\varnothing_{j}$ is the updated value of the current density. $K_{j}$ is the constant amplitude, which is different for various stages of a temperature profile and values are shown in Table 1. $T_{i}$ is programed temperature and $\Delta T_{i}$ is the temperature difference of calculated temperature and predefined program temperature. This loop is repeated at every time step.

The FE simulations were carried out for the three types of heating and cooling strategies. In order to obtain agreement between the FE computed results and the experimental results of temperature profiles, the conduction heat transfer

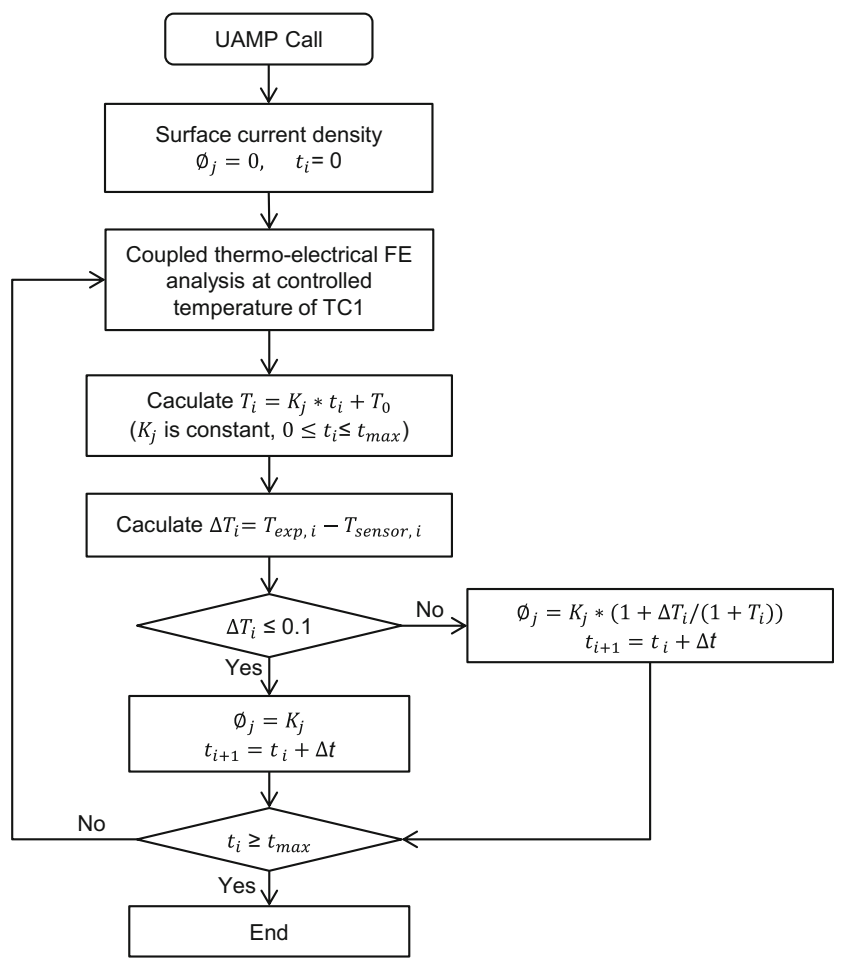

Fig. 9 Work flow of UAMP $\left(\varnothing_{j}\right.$ is the updated value of the current density, $K_{j}$ is the constant amplitude, $T_{i}$ is the programed temperature, $\Delta T_{i}$ is the temperature difference between calculated temperature and predefined program temperature, increment time $t_{i}, \Delta t$ is time step and $t_{\max }$ is the final time step)
Table 1 Values of constant $K_{j}$ in the UAMP subroutine

\begin{tabular}{lllll}
\hline & $\begin{array}{l}\mathrm{K}_{1} \text { (Heating } \\
\text { process) }\end{array}$ & $\begin{array}{l}\mathrm{K}_{2} \text { (Soaking } \\
\text { process) }\end{array}$ & $\begin{array}{l}\mathrm{K}_{3} \text { (Cooling } \\
\text { process) }\end{array}$ & $\begin{array}{l}\mathrm{K}_{4} \text { (Deformation } \\
\text { process) }\end{array}$ \\
\hline Values & 13.0 & 5.0 & 5.2 & 4.5 \\
\hline
\end{tabular}

coefficient was defined as $8000 \mathrm{Wm}^{-2} \mathrm{~K}^{-1}$ and the sink temperature within clamping region was defined as $150^{\circ} \mathrm{C}$. These two values were determined empirically for the best fit of the thermal simulation results to the experimental temperature data obtained for selected positions along the gauge section of the specimen. The initial temperature of all elements was set to the room temperature of $20^{\circ} \mathrm{C}$. Conduction heat transfer was used for the clamping area to simulate heat loss. The gauge area of the specimen was meshed finely and the coarseness of the mesh increased from the centre-line to the clamped end, in order to reduce calculation time. A 4-node linear coupled thermo-electrical tetrahedron element was used.

Full-field temperature distribution was calculated as the central point temperature $\mathrm{TC} 1$ increased to $535^{\circ} \mathrm{C}$, soaked for $1 \mathrm{~min}$ and cooled to $400{ }^{\circ} \mathrm{C}$ at a cooling rate of $100^{\circ} \mathrm{C} / \mathrm{s}$. The results of computed temperature at different thermocouple locations were compared to experimental results measured at the central point temperature $\mathrm{TC} 1$ of $400{ }^{\circ} \mathrm{C}$, as shown in Table 2. Good agreement is noted between the predicted results and experimentally measured results.

Figure 10 shows the full-field temperature distribution for each heating and cooling strategy. All simulation results were obtained for a soaking temperature of $400{ }^{\circ} \mathrm{C}$ after 1 min solution heat treatment at $535{ }^{\circ} \mathrm{C}$ and quenching with a quench rate of $100{ }^{\circ} \mathrm{C} / \mathrm{s}$. In Fig. 10(a), by using of the first type of heating and cooling strategy, the temperature difference between the heated two arms and the other two is around $100{ }^{\circ} \mathrm{C}$. The non-uniform temperature field could cause the heterogeneous deformation on the specimen. The temperature

Table 2 Comparison of experimental and simulated results of temperatures at different locations on specimens of AA6082 for different types of heating and cooling strategies

\begin{tabular}{|c|c|c|c|c|c|}
\hline \multicolumn{2}{|c|}{ Temperatures $\left({ }^{\circ} \mathrm{C}\right)$} & \multirow{2}{*}{$\begin{array}{l}\begin{array}{l}\text { Location } \\
\text { TC1 }\end{array} \\
398.63\end{array}$} & \multirow{2}{*}{$\begin{array}{l}\begin{array}{l}\text { Location } \\
\text { TC2 }\end{array} \\
398.76\end{array}$} & \multirow{2}{*}{$\begin{array}{l}\text { Location } \\
\text { TC3 } \\
409.73\end{array}$} & \multirow{2}{*}{$\begin{array}{l}\text { Location } \\
\text { TC4 }\end{array}$} \\
\hline 1st type & $\begin{array}{l}\text { Experimental } \\
\text { results }\end{array}$ & & & & \\
\hline & $\begin{array}{l}\text { Simulated } \\
\text { results }\end{array}$ & 400.01 & 395.23 & 407.89 & \\
\hline \multirow[t]{2}{*}{ 2nd type } & $\begin{array}{l}\text { Experimental } \\
\text { results }\end{array}$ & 399.07 & 402.86 & 401.01 & 382.07 \\
\hline & $\begin{array}{l}\text { Simulated } \\
\text { results }\end{array}$ & 400.87 & 399.69 & 396.88 & 380.04 \\
\hline \multirow[t]{2}{*}{ 3rd type } & $\begin{array}{l}\text { Experimental } \\
\text { results }\end{array}$ & 399.98 & 415.54 & & \\
\hline & $\begin{array}{l}\text { Simulated } \\
\text { results }\end{array}$ & 400.41 & 418.37 & & \\
\hline
\end{tabular}


difference between region A and region $\mathrm{B}$ is around $30{ }^{\circ} \mathrm{C}$, which may cause the fracture occur in the two arms with relatively higher temperatures. Thus this heating strategy is not recommended.

In Fig. 10(b), an isothermal temperature field can be observed within the gauge region but different temperature distributions exist on the four arms of the specimen. The temperature distribution outside the recess region is not symmetric and consistent because the gradient of electrical potential on the specimen decreased from the positive electrodes to the negative electrodes. The temperature distribution outside the gauge region would have an effect on the deformation of the central region. The average temperature in region $\mathrm{A}$ is $4{ }^{\circ} \mathrm{C}$ lower than that in region $\mathrm{B}$ along the section I-I and about $20{ }^{\circ} \mathrm{C}$ higher than that in region $\mathrm{C}$ along the section II-II. A

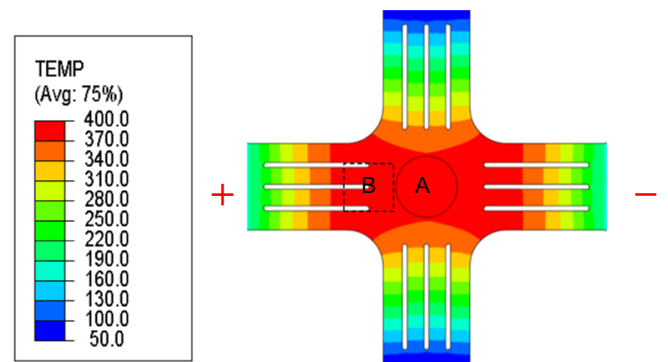

(a) The temperature field with the heating and cooling strategy of Type 1 (Dimension of region B is $12 * 12 \mathrm{~mm}$ )

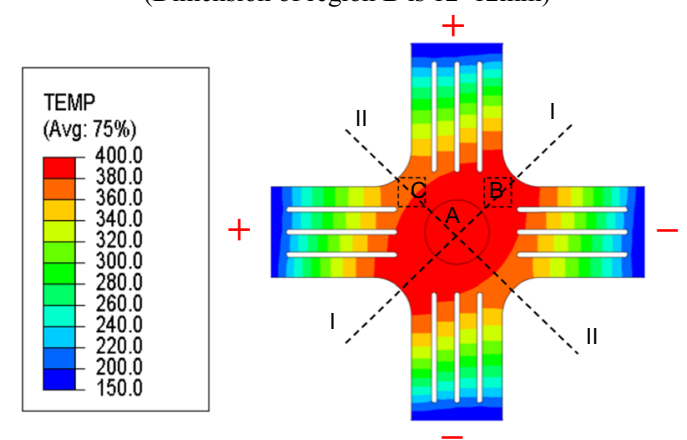

(b) The temperature field with the heating and cooling strategy of Type 2 (Dimensions of region $\mathrm{B}$ and $\mathrm{C}$ are $6 * 6 \mathrm{~mm}$ )

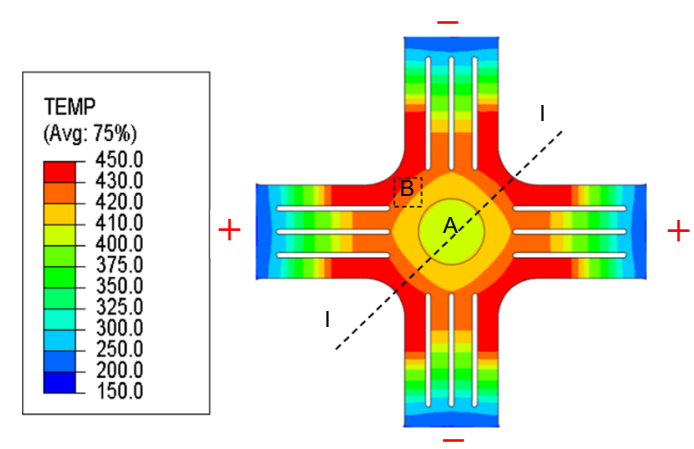

(c) The temperature field with the heating and cooling strategy of Type 3 (Dimension of region B is $6 * 6 \mathrm{~mm}$ )

Fig. 10 Simulated temperature distribution results (Dashed lines I-I and II-II are lines of symmetry; '+' represents positive electrode and '-' represents negative electrode; ' $\mathrm{A}$ ' is the gauge region) higher temperature within the gauge area is beneficial to inducing fracture starts in this region.

In Fig. 10(c), the temperature field is symmetrical and uniform within regions $\mathrm{A}$ and $\mathrm{B}$. The temperature difference within region $\mathrm{A}$ is $8.2^{\circ} \mathrm{C}$. The average temperature in region $\mathrm{A}$ is $32.8^{\circ} \mathrm{C}$ which is lower than the maximum temperature in region $\mathrm{B}$ along section I-I. When the average temperature in the central region is much lower than that on the arms of the specimen, the arms might deform prematurely.

The thermo-electrical FE model was used to obtain the temperature fields on specimens. Based on the analysis above, the second type strategy is the most acceptable one compared with the other two since fractures could occur in the central region but not in the arms by consideration of temperature distribution on a specimen.

\section{Biaxial Tensile Tests}

The formability tests using the new in-plane biaxial tensile testing system were conducted, using both uniaxial and cruciform specimens, at the designated temperatures and strain rates after cooling to verify the feasibility of this new test method. All three types of heating and cooling strategy were used. Fracture occurred in the arms of a specimen or around the ends of slots when the first and third strategies were used. Localised necking started from the central gauge section only with the second type of heating and cooling strategy. Exemplar DIC results of one deformed specimen, using the second type of heating/cooling strategy, is shown in Fig. 11. The specimen was stretched at $400{ }^{\circ} \mathrm{C}$ and a strain rate of 0.1 /s after solution heat treatment at $535^{\circ} \mathrm{C}$ and quenching. Higher values of strain level exist in the central region than in surrounding regions, which indicate the location of fracture.

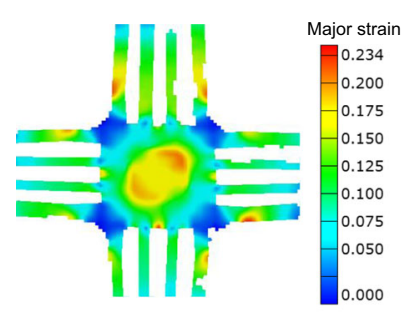

(a) DIC results of major strain

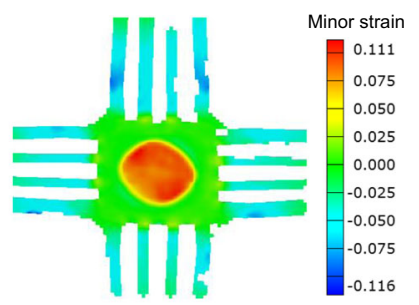

(b) DIC results of minor strain

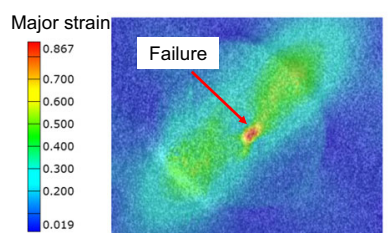

(c) The location of failure

Fig. 11 DIC results of major strain and minor strain distribution for a cruciform specimen tested at a temperature of $400^{\circ} \mathrm{C}$ and strain rate of 0.1 $/ \mathrm{s}$, using the second type of heating and cooling strategy 


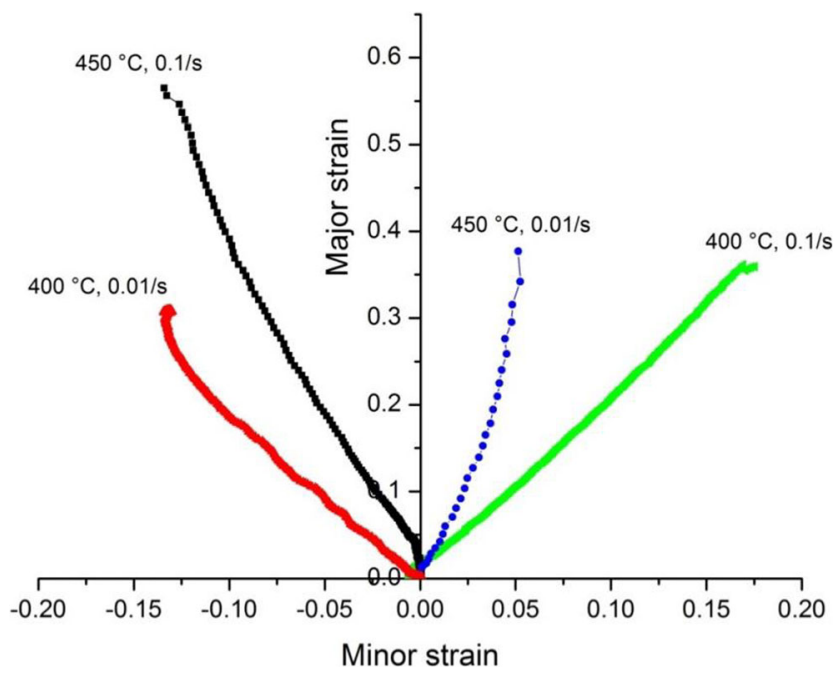

Fig. 12 Strain paths showing the proportional loading of AA6082 under different conditions

Since strain-based FLDs are highly strain path dependent, the linearity of strain path for each test condition was verified by analysing the DIC results. Representative strain paths in Fig. 12 show linearity was achieved. The equi-biaxial condition is difficult to achieve experimentally because of nonuniformity of temperature distribution on the specimen and the existence of shear strain on the central region of the cruciform specimen.

In order to monitor the onset of necking, the international standard ISO 12004-2 [43] was used to define forming limit. This standard was embedded in the ARAMIS system of DIC. Three virtual section lines, $2 \mathrm{~mm}$ apart, were created perpendicular to the crack within the gauge region and major strain and minor strain values were derived along them. An inverse parabola was fitted through two fit windows on both sides of the crack. The two fitting windows were determined by using the second derivative of the strain values against the corresponding positions. The peak points of the fitted curve were used as the

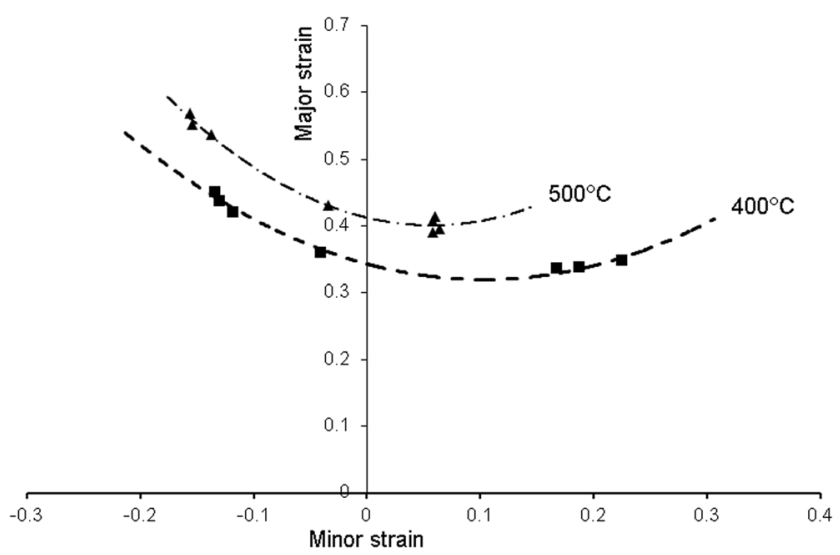

Fig. 13 Forming limit curves for AA6082 after solution heat treatment and cooling to temperatures of 400 and $500{ }^{\circ} \mathrm{C}$ with an effective strain rate of $0.1 / \mathrm{s}$ major strain and minor strain of forming limits. The representative forming limit curves of AA6082 at deformation temperatures of 400 and $500{ }^{\circ} \mathrm{C}$ and a strain rate of $0.1 / \mathrm{s}$ were obtained and are shown in Fig. 13. Dashed lines were obtained through the polynomial fitting algorithm. An equi-biaxial strain state was not achievable due to non-uniform temperature and the existence of unavoidable shear in gauge region. The generated forming limit curves prove that the new apparatus and specimens of appropriate design provide an effective method to experimentally determine forming limits of heated sheet alloys under hot stamping and cold die quenching conditions.

\section{Conclusions}

In order to overcome the weaknesses associated with conventional methods for the determination of FLDs at elevated temperatures for application to industrial hot stamping and cold die quenching processes, a new in-plane biaxial testing system was designed and used on a Gleeble materials simulator machine. This new testing system enables formability data to be generated under complex heating and cooling conditions. Designed uniaxial and cruciform specimens were used in formability tests under different linear strain paths. By comparison of temperature distributions obtained from different types of resistance heating and air cooling strategies, it was found that connecting two adjacent arms of the cruciform specimen to positive electrodes gave the most acceptable temperature field within the gauge region. Specimen design could be further improved since the temperature distribution on the arms of the cruciform specimen is not exactly uniform and symmetric. Representative forming limit curves for AA6082 at temperatures of 400 and $500{ }^{\circ} \mathrm{C}$ and strain rate of $0.1 / \mathrm{s}$ were obtained on solution heat treated and cooled material, which proved the feasibility of this novel method for the determination of FLD of sheet metals under hot stamping conditions. This method can be used to determine the hot formability of many sheet metals up to a maximum temperature of $1000^{\circ} \mathrm{C}$, on a Gleeble materials simulator.

Acknowledgments Financial support from Impression Technologies Ltd for this research project is gratefully acknowledged by the authors. In addition, the research was supported by the European Union's Seventh Framework Programme (FP7/2007-2013) under grant agreement No. 604240, project title 'An industrial system enabling the use of a patented, lab-proven materials processing technology for Low Cost forming of Lightweight structures for transportation industries (LoCoLite)'.

Open Access This article is distributed under the terms of the Creative Commons Attribution 4.0 International License (http:// creativecommons.org/licenses/by/4.0/), which permits unrestricted use, distribution, and reproduction in any medium, provided you give appropriate credit to the original author(s) and the source, provide a link to the Creative Commons license, and indicate if changes were made. 


\section{References}

1. Li N, Sun C, Guo N, Mohamed M, Lin J, Matsumoto T, Liu C (2016) Experimental investigation of boron steel at hot stamping conditions. J Mater Process Technol 228:2-10. doi:10.1016/j. jmatprotec.2015.09.043

2. Milkereit B, Wanderka N, Schick C, Kessler O (2012) Continuous cooling precipitation diagrams of $\mathrm{Al}-\mathrm{Mg}-\mathrm{Si}$ alloys. Mater Sci Eng A 550:87-96. doi:10.1016/j.msea.2012.04.033

3. Miller WS, Zhuang L, Bottema J, Wittebrood AJ, De Smet P, Haszler A, Vieregge A (2000) Recent development in aluminium alloys for the automotive industry. Mater Sci Eng 280(1):37-49. doi:10.1016/S0921-5093(99)00653-X

4. George R, Bardelcik A, Worswick MJ (2012) Hot forming of boron steels using heated and cooled tooling for tailored properties. $\mathrm{J}$ Mater Process Technol 212(11):2386-2399. doi:10.1016/j. jmatprotec.2012.06.028

5. Karbasian H, Tekkaya AE (2010) A review on hot stamping. J Mater Process Technol 210(15):2103-2118. doi:10.1016/j. jmatprotec.2010.07.019

6. El Fakir O, Wang L, Balint D, Dear JP, Lin J, Dean TA (2014) Numerical study of the solution heat treatment, forming, and indie quenching (HFQ) process on AA5754. Int J Mach Tool Manuf 87:39-48. doi:10.1016/j.ijmachtools.2014.07.008

7. El Fakir O, Chen S, Wang LL, Balint D, Dear JP, Lin JG (2013) Numerical investigation on the hot forming and cold-die quenching of an aluminium-magnesium alloy into a complex component. Mater Sci Forum 765:368-372. doi:10.4028/www.scientific.net/ MSF.765.368

8. Foster A, Dean TA, Lin J (2012) Process for forming aluminium alloy sheet component. UK Patent WO2010/032002 A1

9. Lin J, Dean TA, Garrett RP (2008) A process in forming high strength and complex-shaped Al-alloy sheet components. UK Patent WO2008059242

10. Mohamed MS, Foster AD, Lin J, Balint DS, Dean TA (2012) Investigation of deformation and failure features in hot stamping of AA6082: experimentation and modelling. Int $\mathrm{J}$ Mach Tool Manuf 53(1):27-38. doi:10.1016/j.ijmachtools. 2011.07.005

11. Lin J, Dean TA, Foster AD, Wang L, Balint D (2011) A method of forming a component of complex shape from aluminium alloy sheet. UK Patent WO2011/058332 A1

12. Keeler SP, Backofen WA (1963) Plastic instability and fracture in sheets stretched over rigid punches. ASM Trans Q 56(1):25-48

13. Srivastava A, Bower AF, Hector LG, Carsley JE, Zhang L, AbuFarha F (2016) A multiscale approach to modeling formability of dual-phase steels. Model Simul Mater Sci Eng 24(2):025011. doi: 10.1088/0965-0393/24/2/025011

14. Hsu E, Carsley JE, Verma R (2008) Development of forming limit diagrams of aluminum and magnesium sheet alloys at elevated temperatures. J Mater Eng Perform 17(3):288-296. doi:10.1007/ s11665-007-9196-y

15. Olsen TY (1920) Machines for ductility testing. Proc Am Soc Mater 20:398-403

16. Raghavan KS (1995) A simple technique to generate in-plane forming limit curves and selected applications. Metall Mater Trans A 26(8):2075-2084

17. 17. Nakazima K, Kikuma T, Hasuka K (1968) Study on the formability of steel sheets. Yawata Technical Report 264.

18. Ayres RA, Wenner ML (1979) Strain and strain-rate hardening effects in punch stretching of 5182-0 aluminum at elevated temperatures. Metall Trans A 10(1):41-46

19. Bagheriasl R (2012) Formability of aluminum alloy sheet at elevated temperature. University of Waterloo
20. Sène NA, Balland P, Arrieux R, Bouabdallah K (2012) An experimental study of the microformability of very thin materials. Exp Mech 53(2):155-162. doi:10.1007/s11340-012-9623-3

21. Min J, Lin J, Cao Y, Bao W, Lu Z (2010) Effect of necking types of sheet metal on the left-hand side of forming limit diagram. J Mater Process Technol 210(8):1070-1075. doi:10.1016/j.jmatprotec. 2010.02.018

22. Abu-Farha F, Verma R, Hector LG (2012) High temperature composite forming limit diagrams of four magnesium AZ31B sheets obtained by pneumatic stretching. J Mater Process Technol 212(6):1414-1429. doi:10.1016/j.jmatprotec.2012.01.008

23. Marciniak Z, Kuczynski K (1967) Limit strains in the processes of stretch-forming sheet metal. Int J Mech Sci 9(9):609-620

24. Li D, Ghosh AK (2004) Biaxial warm forming behavior of aluminum sheet alloys. J Mater Process Technol 145(3):281-293. doi:10. 1016/j.jmatprotec.2003.07.003

25. Kim HS, Koc M, Ni J, Ghosh A (2006) Finite element modeling and analysis of warm forming of aluminum alloys - validation through comparisons with experiments and determination of a failure criterion. J Manuf Sci Eng 128(3):613. doi:10.1115/1.2194065

26. Palumbo G, Sorgente D, Tricarico L (2008) The design of a formability test in warm conditions for an AZ31 magnesium alloy avoiding friction and strain rate effects. Int J Mach Tool Manuf 48(14):1535-1545. doi:10.1016/j.ijmachtools.2008.06.010

27. Hannon A, Tiernan P (2008) A review of planar biaxial tensile test systems for sheet metal. J Mater Process Technol 198(1-3):1-13. doi:10.1016/j.jmatprotec.2007.10.015

28. Leotoing L, Guines D, Zidane I, Ragneau E (2013) Cruciform shape benefits for experimental and numerical evaluation of sheet metal formability. J Mater Process Technol 213(6):856-863. doi: 10.1016/j.jmatprotec.2012.12.013

29. Naka T, Uemori T, Hino R, Kohzu M, Higashi K, Yoshida F (2008) Effects of strain rate, temperature and sheet thickness on yield locus of AZ31 magnesium alloy sheet. J Mater Process Technol 201(13):395-400. doi:10.1016/j.jmatprotec.2007.11.189

30. Lin J, Mohamed M, Balint D, Dean T (2013) The development of continuum damage mechanics-based theories for predicting forming limit diagrams for hot stamping applications. Int $\mathrm{J}$ Damage Mech 23(5):684-701. doi:10.1177/1056789513507731

31. Rodríguez-Millán M, Vaz-Romero A, Rusinek A, RodríguezMartínez JA, Arias A (2014) Experimental study on the perforation process of 5754-H111 and 6082-T6 aluminium plates subjected to normal impact by conical, hemispherical and blunt projectiles. Exp Mech 54(5):729-742. doi:10.1007/s11340-013-9829-Z

32. Garrett R, Lin J, Dean T (2005) An investigation of the effects of solution heat treatment on mechanical properties for AA $6 \mathrm{xxx}$ alloys: experimentation and modelling. Int J Plast 21(8):1640-1657. doi:10.1016/j.ijplas.2004.11.002

33. Coër J, Bernard C, Laurent H, Andrade-Campos A, Thuillier S (2010) The effect of temperature on anisotropy properties of an aluminium alloy. Exp Mech 51(7):1185-1195. doi:10.1007/ s11340-010-9415-6

34. Shao Z, Li N, Lin J, Bai Q (2015) Planar test system. UK Patent

35. Makinde A, Thibodeau L, Neale KW (1992) Development of an apparatus for biaxial testing using cruciform specimens. Exp Mech 32(2):138-144

36. Gozzi J (2005) Experimental investigation of the behavior of extra high strength steel. Exp Mech 45(6):533-540. doi:10.1177/ 0014485105059554

37. Kosai M, Shimamoto A, Yu C, Kobayashi A, Tan P (1996) A biaxial test specimen for crack arrest studies. Exp Mech 36(3): 277-283. doi:10.1007/BF02318019

38. Abu-Farha F, Hector LG Jr, Khraisheh M (2009) Cruciform-shaped specimens for elevated temperature biaxial testing of lightweight materials. JOM 61(8):48-56. doi:10.1007/s11837-009-0121-8 
39. Kelly DA (1976) Problems in creep testing under biaxial stress systems. J Strain Anal Eng Des 11(1):1-6. doi:10.1243/ $03093247 \mathrm{v} 111001$

40. Yu Y, Wan M, Wu X-D, Zhou X-B (2002) Design of a cruciform biaxial tensile specimen for limit strain analysis by FEM. J Mater Process Technol 123(1):67-70. doi:10.1016/S0924-0136(02) 00062-6

41. Mohamed M, Lin J, Foster A, Dean T, Dear J (2014) A new test design for assessing formability of materials in hot stamping. Procedia Eng 81:1689-1694. doi:10.1016/j.proeng.2014.10.214
42. Kardoulaki E, Lin J, Balint D, Farrugia D (2014) Investigation of the effects of thermal gradients present in Gleeble high-temperature tensile tests on the strain state for free cutting steel. J Strain Anal Eng Des 49(7):521-532. doi:10.1177/0309324714531950

43. Metallic materials-sheet and strip-determination of forming limit curves, Part 2: Determination of forming limit curves in the laboratory (2004). vol ISO 12004-2:2008. Int Organ Standard 